endofullerenes are self-assembled chains of $\mathrm{C}_{60}$. The observation of these structures raises the hope that refined processing techniques can be developed to produce them in large quantities.

Brian W. Smith ${ }^{\star}$, Marc Monthioux ${ }^{\star} \dagger$, David E. Luzzi*

* Department of Materials Science and Engineering, University of Pennsylvania, 3231 Walnut Street,

Philadelphia, Pennsylvania 19104-6272, USA

e-mail:luzzi@lrsm.upenn.edu

$\dagger$ †EMES, UPR A-8011 CNRS, BP 4347,

F-31055 Toulouse cedex 4, France

1. Rinzler, A. G. et al. Appl. Phys. A 67, 29-37 (1998).

2. Nikolaev, P., Thess, A., Rinzler, A. G., Colbert, D. T. \& Smalley, R. E. Chem. Phys. Lett. 266, 422-426 (1997)

3. Heiney, P. A. J. Phys. Chem. Solids 53, 1333-1352 (1992).

4. Yakobson, B. I. \& Smalley, R. E. Am. Sci. 85, 324-337 (1997).

\section{How does xenon produce anaesthesia?}

Since the discovery that the gas xenon can produce general anaesthesia ${ }^{1}$ without causing undesirable side effects, we have remained surprisingly ignorant of the molecular mechanisms underlying this clinical activity of an 'inert' gas. Although most general anaesthetics enhance the activity of inhibitory $\mathrm{GABA}_{\mathrm{A}}(\gamma$-aminobutyric acid type-A) receptors ${ }^{2,3}$, we find that the effects of xenon on these receptors are negligible. Instead, xenon potently inhibits the excitatory NMDA ( $N$-methyl-D-aspartate)

receptor channels, which may account for many of xenon's attractive pharmacological properties.

We found that xenon had virtually no effect on $\mathrm{GABA}_{\mathrm{A}}$ receptors. Currents activated by $3 \mu \mathrm{M}$ GABA, both in voltageclamped cultured rat hippocampal neurons and in voltage-clamped PA3 cells ${ }^{4}$ that stably expressed defined $\mathrm{GABA}_{\mathrm{A}}$ subunits, were not significantly affected even by $100 \%$ xenon (to function as a human anaesthetic, the half-maximal effective concentration $\left(\mathrm{EC}_{50}\right)$ is $71 \% \mathrm{v} / \mathrm{v}$; ref. 5 ). Xenon also had little effect on functional GABAreleasing synapses in hippocampal neurons, with $80 \%$ xenon reducing peak inhibitory postsynaptic currents by only $8 \pm 2 \%$. This result indicates that the presynaptic effects of xenon must also be very modest.

Apart from the $\mathrm{GABA}_{\mathrm{A}}$ receptor, the only generally accepted neuronal target of conventional anaesthetics is the NMDA receptor. This subtype of glutamate-activated ionotropic channels is implicated in synaptic mechanisms underlying learning, memory and the perception of pain ${ }^{6}$. The NMDA receptor is also believed to be a target of the intravenous general anaesthetic agent ketamine $e^{7}$, and possibly nitrous oxide . $^{8}$

We therefore looked at the effects of xenon on NMDA-activated currents in cultured hippocampal neurons. We found that $80 \%$ xenon, which will maintain surgical anaesthesia, reduced NMDA-activated currents by about $60 \%$ (Fig. 1a), with no significant change in the NMDA EC 50

Figure 1 Xenon inhibits NMDA receptors in cultured rat hippocampal neurons. a, NMDA activates an inward current (in neurons clamped at $-60 \mathrm{mV}$ ) with an $\mathrm{EC}_{50}$ of $24 \pm 2 \mu \mathrm{M}$ NMDA and a Hill coefficient of $1.2 \pm 0.1$. Xenon inhibited the current by approximately $60 \%$ but did not significantly change either the $\mathrm{EC}_{50}$ or the Hill coefficient. Each data point represents the mean peak current from at least 6 cells. Inset, typical current traces (at $100 \mu \mathrm{M}$ NMDA) in the presence and absence of xenon. b, Xenon selectively inhibits the NMDA-receptormediated component of glutamatergic excitatory postsynaptic currents (EPSCs). Neurons were voltage-clamped at $-60 \mathrm{mV}$; synaptic responses were stimu-
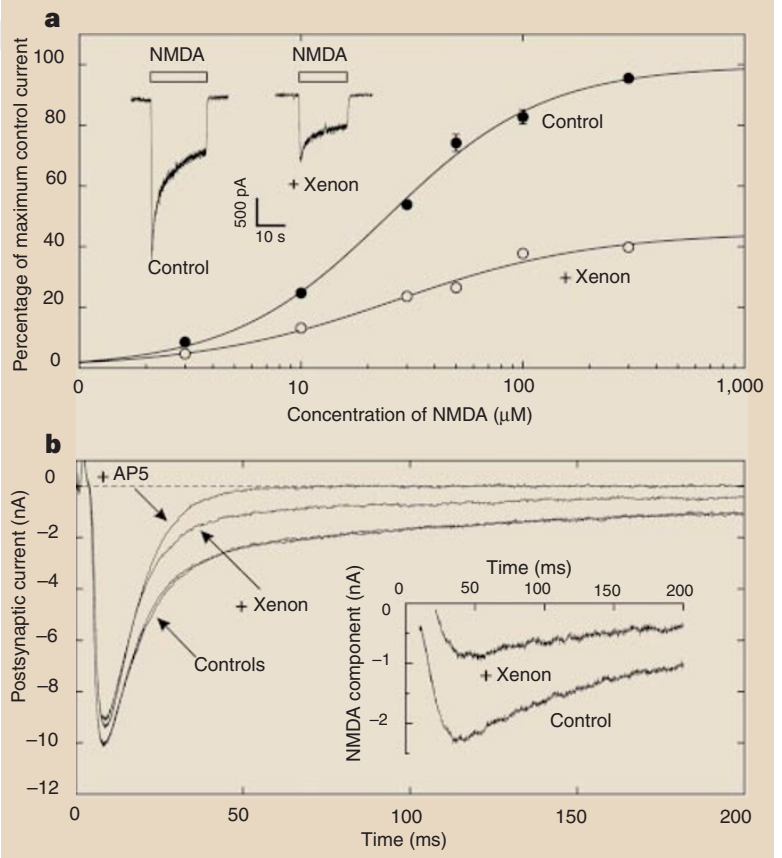

lated by a 2-ms depolarizing pulse to $+20 \mathrm{mV}$. Control glutamatergic EPSCs displayed a characteristic biphasic decay. The slow component was completely blocked by $200 \mu \mathrm{M}$ AP5, leaving the fast component almost unaffected. Inset, the NMDA-receptor-mediated component (the difference between the control EPSC and that in the presence of AP5) and its size in the presence of xenon (calculated by taking the difference between the EPSC in the presence of xenon and that in the presence of AP5). Control solutions were equilibrated at room temperature with $80 \% \mathrm{~N}_{2}$ and $20 \% \mathrm{O}_{2}$, and test solutions with $80 \% \mathrm{Xe}$ and $20 \% \mathrm{O}_{2}$.

value or Hill coefficient. This non-competitive inhibition indicates that xenon should strongly inhibit neural transmission, despite the high glutamate concentrations in synaptic clefts.

We then tested this in microisland cultures of hippocampal neurons that form synapses with themselves (autapses) ${ }^{9}$. A typical glutamatergic postsynaptic current recorded from a hippocampal neuron is shown in Fig. 1b. The control records show a characteristic biphasic time course, with a fast component mediated by non-NMDA receptors and a much slower component mediated by NMDA receptors. This NMDA receptor-mediated component could be readily identified as it was blocked by the highly selective competitive antagonist AP5 (DL-2-amino-5-phosphonopentanoate $)^{10}$.

Addition of $200 \mu \mathrm{M}$ AP5 almost completely blocked the slow component, leaving only a fast component, with a single exponential time course very similar to that of the control fast component. The effect of xenon on the glutamatergic postsynaptic current resembled that of AP5 (Fig. 1b). The slow, NMDA-receptor-mediated component was reduced by over $70 \%$, whereas the fast component barely changed. So, not only did xenon inhibit synaptic NMDA receptors, it had little apparent effect on non-NMDA receptors.

If xenon exerts its effects by inhibiting NMDA receptors, then this explains some important features of its pharmacological profile, particularly as NMDA-receptor antagonists can relieve pain and cause amnesia, which are features of xenon anaesthesia. Like nitrous oxide ('laughing gas'), which may also act, at least partly, on NMDA receptors ${ }^{8}$, xenon can induce a state of euphoria. Other neuronal targets for xenon may emerge, but its powerful inhibition of the NMDA receptor is likely to be instrumental in the anaesthetic and analgesic effects of this 'inert' gas.

N. P. Franks, R. Dickinson, S. L. M. de Sousa, A. C. Hall, W. R. Lieb

Biophysics Section,

The Blackett Laboratory,

Imperial College of Science, Technology and Medicine, Prince Consort Road,

London SW7 2BZ, UK

e-mail:n.franks@ic.ac.uk

1. Cullen, S. C. \& Gross, E. G. Science 113, 580-582 (1951).

2. Franks, N. P. \& Lieb, W. R. Nature 367, 607-614 (1994).

3. Mihic, S. J. et al. Nature 389, 385-389 (1997).

4. Hadingham, K. L. et al. Proc. Natl Acad. Sci. USA 89, 6378-6382 (1992).

Cullen, S. C., Eger, E. I. II, Cullen, B. F. \& Gregory, P. Anesthesiology 31, 305-309 (1969).

6. Rang, H. P., Dale, M. M. \& Ritter, J. M. Pharmacology 3rd edn (Churchill Livingstone, Edinburgh, 1995).

7. Anis, N. A., Berry, S. C., Burton, N. R. \& Lodge, D. Br. J. Pharmacol. 79, 565-575 (1983).

8. Jevtovic-Todorovic, V. et al. Nature Med. 4, 460-464 (1998).

9. Bekkers, J. M. \& Stevens, C. F. Proc. Natl Acad. Sci. USA 88, 7834-7838 (1991).

10. Watkins, J. C. \& Evans, R. H. Annu. Rev. Pharmacol. Toxicol. 21, 165-204 (1981). 